\title{
Preparation of Silver Nanoparticles Suitable for Textile Finishing Processes to Produce Textiles with Strong Antibacterial Properties against Different Bacteria Types
}

\author{
Boris Mahltig ${ }^{\mathrm{a}}$, Marianne Reibold ${ }^{\mathrm{b}}$, Emanuel Gutmann ${ }^{\mathrm{b}}$, Torsten Textor ${ }^{\mathrm{c}}$, \\ Jochen Gutmann ${ }^{\mathrm{c}}$, Helfried Haufe ${ }^{\mathrm{d}}$, and Hajo Haase ${ }^{\mathrm{e}}$ \\ ${ }^{a}$ University of Applied Sciences, Faculty of Textile and Clothing Technology, Webschulstraße 31, \\ 41065 Mönchengladbach, Germany \\ b Technische Universität Dresden, Institut für Strukturphysik, 01062 Dresden, Germany \\ ${ }^{c}$ Deutsches Textilforschungszentrum Nord-West e. V., DTNW e. V., Adlerstraße 1, 47798 Krefeld, \\ Germany \\ ${ }^{\mathrm{d}}$ Gesellschaft zur Förderung von Medizin-, Bio- und Umwelttechnologien e. V., GMBU e. V., \\ Department of Functional Coatings, Postfach 520165, 01317 Dresden, Germany \\ e Institute of Immunology, Medical Faculty, RWTH Aachen University, Pauwelsstraße 30, \\ 52074 Aachen, Germany
}

Reprint requests to Prof. Dr. Boris Mahltig. Fax: +49-2161-186-6013.

E-mail: boris.mahltig@hs-niederrhein.de

Z. Naturforsch. 2011, 66b, 905 -916; received June 27, 2011

This study describes the development of a preparation technique for silver nanoparticles useable as antimicrobial material which is especially useful for textile treatment to realize antimicrobial fabrics. The silver particles need to be prepared by reduction of $\mathrm{AgNO}_{3}$ under moderate conditions and with a moderate and non-toxic reductive agent. Comparative investigations were carried out with silver particles prepared by a solvothermal process or with $\mathrm{NaBH}_{4}$ as reductive agent.

Particularly, suitable silver solutions are obtained by stabilizing the silver particles with polyvinylpyrollidone PVP of high molecular weight $\left(M_{\mathrm{W}} \sim 360000 \mathrm{~g} \mathrm{~mol}^{-1}\right)$ and the use of the non-toxic reductive agents ascorbic acid and fructose. Under these conditions the diameters of the silver particles are in the range of 10 to $30 \mathrm{~nm}$ as determined by HR-TEM. The formation of elemental silver has been verified by transmission electron microscopy (TEM), X-ray diffraction (XRD) and optical spectroscopy. The properties of silver particle-containing liquids were investigated by using UV/Vis spectroscopy and dynamic light scattering. Further information on particle size and size distribution was gained through SEM investigations. The prepared solutions of silver nanoparticles can be applied easily onto textiles as liquid coating agents. All prepared textile samples exhibited a high antimicrobial activity against Escherichia coli. However, only few solutions containing silver particles of smaller size exhibit high antimicrobial activity also against other types of bacteria such as Staphylococcus aureus and Streptococcus pneumoniae. Because of this high antimicrobial potential gained with silver solutions prepared in a simple process without usage of toxic components, the developed materials offer a broad range of potential applications.

Key words: Silver, Coatings, Textile, Antimicrobial, Nanoparticles

\section{Introduction}

Silver-containing materials are probably the most prominent example for antimicrobial materials with a broad variety of prospective applications. The main reason for this is the strong antimicrobial efficiency of silver against different types of harmful pathogens $[1-4]$. For this, silver-doped sol-gel coatings are able to prevent the biofilm formation of bacteria on different types of coated surfaces [5,6]. Practical applications of silver-containing materials are reported for silver coat- ings of self-sterilizing silicon catheters [7] or for filters [8]. Interesting materials can be made of silvercontaining silica spheres, for which a preparation by spray drying has recently been reported $[9,10]$.

For many practical applications in the medical sector the use of silver as an antimicrobial agent for textile modification is advantageous. Silver-doped glasscoated sutures can be used for tissue engineering and wound healing applications [11]. In addition, textiles used as antimicrobial barriers for wound dressing can be realized [12]. A special field for application is the 
treatment of atopic dermatitis by silver-containing textiles. Atopic dermatitis is worsened by infection of the skin with Staphylococcus aureus. Silver-containing textiles have been observed to reduce S.aureus in a few days and lead to a positive clinical effect for a faster clearance of atopic dermatitis [13]. Because of these interesting applications and the proposed high economic significance of silver-containing antimicrobial textiles many groups world wide are working on the realization of such materials by different methods [14-19].

One method to apply silver onto textiles is the use of colloid silver nanoparticles, which can be prepared in solution by the reduction of dissolved silver nitrate. These solutions containing highly dispersed colloidal silver can be used as liquid coating agents in traditional processes of textile finishing. One important issue for the preparation of silver particles by reduction is that the growth of the particles has to be limited to a certain size to avoid the fast deposition and sedimentation of the silver, as it could be expected for larger silver particles of micrometer size. For stabilization of small silver particles to prevent an unlimited growth, the silver particles have to be separated from each other to avoid growing processes, as $e . g$. Ostwald ripening. This kind of separation can be achieved by different means, as for example by aminoalcohols or a combination of silica nanoparticles with aminoalcohols [20,21]. Other groups reported the use of surfactants such as sodium dodecyl sulfate (SDS) for the stabilization of small silver particles [22, 23].

Another interesting approach is the use of polymeric stabilizers such as polyvinylpyrollidone (PVP), which has been used for the preparation of colloidal metal particles for decades [24]. The use of PVP in the preparation of elemental silver particles as a stabilizer for the formed and growing particles has been reported by many different groups [25-29]. It is suggested that PVP prevents the aggregation of silver particles and their grain growth because of a steric effect hindering the silver particles to meet each other [25]. For this, the PVP is attached to the surface of the silver particles by coordinative binding of both the nitrogen and oxygen function of the amide group of the repeating unit of this polymer. It is supposed that the coordination by the nitrogen atoms of PVP is more predominant for silver particles with diameters smaller than $50 \mathrm{~nm}$. In contrast, the coordination of both nitrogen and oxygen atoms is supposed to be more important for the stabilization of larger silver particles [26]. A common technique for the formation of silver particles in the presence of PVP is the so-called polyol process. During this process the formation of silver particles is performed from a solution of $\mathrm{AgNO}_{3}$ and PVP in a highboiling alcohol. As an alcohol for example ethyleneglycol can be used, which tolerates reaction temperatures up to $194^{\circ} \mathrm{C}$, because of the high boiling temperature of this solvent [30-33]. In this polyol process the ethylene-glycol fulfills two functions. First it is the solvent, which enables high boiling temperatures necessary if a weak reductive agent is used for the reduction of $\mathrm{AgNO}_{3}$ to elemental silver. Second, the ethyleneglycol acts as a weak reductive agent itself, such that the addition of further reductive compounds is not necessary [31].

Different compounds have been described as reductive agents for the preparation of monodispersed silver particles [34]. For alcohols and polyols a slow reductive rate has been observed. Hence, reactions have to be performed at temperatures significantly higher than $70{ }^{\circ} \mathrm{C}$. If the silver ions are bound in a complex, e.g. with PVP, usually stronger reductive agents or higher reaction temperatures are needed to allow the reduction. For this, it is not possible to prepare silver particles by reduction of $\mathrm{AgNO}_{3}$ with ethanol in the presence of PVP under reflux conditions. The reaction has to be performed at temperatures higher than $130^{\circ} \mathrm{C}$ under solvothermal conditions [29]. By contrast, the polyol process can be realized without solvothermal conditions under normal pressure.

For economic reasons, however, the formation of silver particles at temperatures lower than $100{ }^{\circ} \mathrm{C}$ is preferred. The polyol process also has disadvantages for the preparation of liquid coating agents especially for substrates such as textiles, papers or polymer foils. To replace the polyol solvent after application of the solution on the substrates, usually higher curing temperatures are necessary, because of the higher boiling point of the polyol. These higher curing temperatures can damage the coated substrate and lead to higher energy consumption and longer process times, which means higher costs in industrial processes.

Due to these facts, there is a strong demand to realize the preparation of PVP-stabilized silver particles at lower temperatures in a solvent exhibiting a lower boiling point. The lower process temperatures can be reached by addition of stronger reductive agents, as for example $\mathrm{NaBH}_{4}$, formaldehyde or hydrazine hydrate [34-36]. However, these reductive agents have several disadvantages as they are toxic and lead to the 
Table 1. Overview on tested recipes: preparation conditions and properties.

\begin{tabular}{|c|c|c|c|c|c|c|}
\hline Recipe & Reductive agent & $\begin{array}{l}\text { Type of } \\
\text { PVP }\end{array}$ & $\begin{array}{l}\text { Process } \\
\text { temperature } \\
\text { and time }\end{array}$ & Visible performance & $\begin{array}{l}\text { Position and } \\
\text { intensity of } \\
\text { absorption } \\
\text { maximum }\end{array}$ & $\begin{array}{l}\text { Maximum in } \\
\text { particle size } \\
\text { distribution }\end{array}$ \\
\hline$\overline{\mathrm{N} 1}$ & none & K90 & $120^{\circ} \mathrm{C} ; 1 \mathrm{~h}$ & clear liquid & no maximum & not determined \\
\hline $\mathrm{N} 2$ & none & K90 & $140{ }^{\circ} \mathrm{C} ; 1 \mathrm{~h}$ & brown and turby solution & $435 \mathrm{~nm} ; \mathrm{A}=1.6$ & $24 \mathrm{~nm}$ \\
\hline N3 & none & K90 & $160{ }^{\circ} \mathrm{C} ; 1 \mathrm{~h}$ & brown and turby solution & $433 \mathrm{~nm} ; \mathrm{A}=2.1$ & $22 \mathrm{~nm}$ \\
\hline A1 & ascorbic acid & $\mathrm{K} 25$ & $80{ }^{\circ} \mathrm{C} ; 6 \mathrm{~h}$ & black solution, fast precipitation & no maximum & not determined \\
\hline A2 & ascorbic acid & K90 & $80{ }^{\circ} \mathrm{C} ; 6 \mathrm{~h}$ & brown and turby solution & $446 \mathrm{~nm} ; \mathrm{A}=1.8$ & $28 \mathrm{~nm}$ \\
\hline $\mathrm{F} 1$ & fructose & $\mathrm{K} 25$ & $80{ }^{\circ} \mathrm{C} ; 6 \mathrm{~h}$ & brown and turby solution & $436 \mathrm{~nm} ; \mathrm{A}=1.9$ & $10 \mathrm{~nm}$ \\
\hline $\mathrm{F} 2$ & fructose & K90 & $80{ }^{\circ} \mathrm{C} ; 6 \mathrm{~h}$ & brown and turby solution; slow sedimentation & $420 \mathrm{~nm} ; \mathrm{A}=1.2$ & $21 \mathrm{~nm}$ \\
\hline B1 & $\mathrm{NaBH}_{4}$ & $\mathrm{~K} 25$ & $80{ }^{\circ} \mathrm{C} ; 6 \mathrm{~h}$ & black solution; slow sedimentation & no maximum & $105 \mathrm{~nm}$ \\
\hline $\mathrm{B} 2$ & $\mathrm{NaBH}_{4}$ & K90 & $80^{\circ} \mathrm{C} ; 6 \mathrm{~h}$ & black solution; slow sedimentation & $396 \mathrm{~nm} ; \mathrm{A}=1.5$ & $48 \mathrm{~nm}$ \\
\hline
\end{tabular}

formation of rapidly growing larger particles which are unstable in solution resulting in fast sedimentation. For most coating processes solutions or dispersions have to be stable over a longer period of time to guarantee a homogeneous application of the coating.

The aim of the present study was to develop an approach to the preparation of silver particles in the presence of PVP at low process temperature by using a non-toxic and medium reductive agent. For this purpose, the compounds fructose and ascorbic acid were evaluated as reductive agents. The performance of the solutions and the quality of the silver particles were evaluated by optical and microscopic methods and compared to conventional methods. In addition to developing a suitable chemical production process and the physical investigation of material properties, it was the aim to evaluate the properties of the prepared silver particles as useful bactericidal agents.

\section{Experimental Section}

Preparation of silver particles and application onto textile

Silver particles stabilized in solution have been prepared by reduction of $\mathrm{AgNO}_{3}$ using the moderate and non-toxic reductive agents fructose or ascorbic acid. The preparation started from a $1 \mathrm{wt} .-\%$ ethanolic solution of polyvinylpyrrolidone (PVP). To $100 \mathrm{~mL}$ of this PVP solution $1 \mathrm{~g} \mathrm{AgNO}_{3}$ dissolved in few $\mathrm{mL}$ of distilled water was added under vigorous stirring. Finally an amount of $0.5 \mathrm{~g}$ of the reductive agent dissolved in few $\mathrm{mL}$ of distilled water was added. As polyvinylpyrrolidone two different types of this polymer were used alternatively. First the PVP type K25 (supplier: Carl Roth GmbH, Germany) with lower molecular weight $\left(M_{\mathrm{w}} \sim 24000 \mathrm{~g} \mathrm{~mol}^{-1}\right)$ was employed. Second, the PVP type K90 (supplier: Fluka, Germany) with higher molecular weight $\left(M_{\mathrm{w}} \sim 360000 \mathrm{~g} \mathrm{~mol}^{-1}\right)$ was chosen. The combinations of different PVP types and reductive agents are listed in Table 1. These solutions were further stirred for $15 \mathrm{~min}$, followed by heating under reflux for $6 \mathrm{~h}$ at $80^{\circ} \mathrm{C}$. After this heating period the solution was cooled to r.t. and visually evaluated with respect to coloration and sedimentation behavior (Table 1).

Alternatively to the medium reductive agents fructose and ascorbic acid, the stronger reductive agent $\mathrm{NaBH}_{4}$ was also used under the same the conditions as a reference system (Table 1).

As another reference, silver particles were prepared from $\mathrm{AgNO}_{3}$ in a solvothermal process according to an earlier developed protocol, without the need of addition of a classical reductive agent [29]. For this purpose, a solution of $1 \mathrm{~g}$ PVP type $\mathrm{K} 90$ and $1 \mathrm{~g} \mathrm{AgNO}_{3}$ in $100 \mathrm{~mL}$ ethanol and $3 \mathrm{~mL}$ water was treated under solvothermal conditions with process temperatures between 120 up to $160{ }^{\circ} \mathrm{C}$ (Table 1). This solvothermal process was performed in a steel autoclave of Berghof Instruments GmbH (HochdruckLaborreaktor BR-500). This autoclave contains an electric heating unit and a $500-\mathrm{mL}$ Teflon vessel with a mechanical stirrer. The process temperatures were set for $1 \mathrm{~h}$. The heating and cooling lasted about $30 \mathrm{~min}$ and $3 \mathrm{~h}$, respectively.

All solutions were applied in the same way onto textile and glass substrates. As textile, viscose made from multifilament yarn (supplied by KOB-Wolfstein, Germany) with a weight of $240 \mathrm{~g} / \mathrm{m}^{2}$ was used for coatings as received. Glass substrates were obtained from Menzel GmbH, Braunschweig, Germany. The application onto viscose fabrics was performed by dip-coating. After dipping, the samples were dried at r.t. and annealed at a temperature of $120{ }^{\circ} \mathrm{C}$ for $30 \mathrm{~min}$. The treated viscose fabrics were used for evaluation of antimicrobial activity, but also for investigations with scanning electron microscopy. The coatings on glass plates were used for XRD evaluations after drying the samples at r.t. for at least $2 \mathrm{~h}$.

\section{Analytical methods}

The optical transmission spectra of the silver-containing solutions were determined using a Cary $50 \mathrm{Scan} \mathrm{UV} / \mathrm{Vis}$ spectrophotometer from Varian. With the exception of recipe 
$\mathrm{N} 1$, all solutions were diluted for these measurements with ethanol in a ratio of $1: 100$. For determination of the distribution of silver particle diameters in the products, dynamic light scattering (DLS) was performed using a device Zetasizer 1000 Malvern Instruments, the silver-containing solutions being diluted by ethanol in a ratio of $1: 100$ to reduce the turbidity of the liquids. To evaluate any formation of crystalline silver by the reduction, X-ray diffraction measurements (XRD) were performed with silver-containing solutions deposited on glass plates and dried. An X-ray diffractometer URD 6 (Seifert FPM) was used. The diffraction patterns were analyzed qualitatively using the PDF-2 database [37].

High-resolution transmission electron microscopy (HR-TEM) was performed to determine size and morphology of the silver particles. These samples were prepared on 200 mesh copper grids containing a graphite membrane of $20 \mathrm{~nm}$ thickness (supplied by Plano GmbH, Germany). A drop of the silver-containing liquid was placed on the copper grid and dried at r.t. for at least $24 \mathrm{~h}$. The as-prepared samples were then investigated using a Philips CM30 transmission microscope.

Scanning electron microscopy (SEM) was used to investigate the topography of the fiber surface after application of the silver-containing liquids. By means of SEM also information on size and morphology of the formed silver particles was gained. These measurements were performed by a SEM microscope S3400N. Sputtering with tungsten was performed prior to the SEM investigations by using a sputtercoater Emitech K500X.

\section{Testing of antimicrobial activity}

Glycerol stocks $(10 \mu \mathrm{L})$ of Escherichia coli (strain BL-21), Staphylococcus aureus and Streptococcus pneumoniae were grown over night in $75 \mathrm{~mL}$ LB medium. For testing their impact on viability, silver-coated textile samples (6 mm diameter) were placed in sterile 24-multiwell cell culture plates (Falcon \#353047) together with $1 \mathrm{~mL}$ bacterial suspension (diluted $1: 250$ in LB medium) per well and incubated for $4 \mathrm{~h}$ at $37{ }^{\circ} \mathrm{C}$, rotating at $120 \mathrm{rpm}$ in an orbital incubator. Subsequently, viability was tested by measuring the reduction of methylthiazolyldiphenyl-tetrazolium bromide (MTT) as previously described [38]. Cells were incubated with $0.01 \%(\mathrm{w} / \mathrm{v})$ MTT in LB medium for $5 \mathrm{~min}$, followed by lysis in isopropanol and determination of the absorption at $570 \mathrm{~nm}$.

\section{Results and Discussion}

\section{Performance of silver-containing solutions}

The performance of the silver-containing solutions after the reductive process is finished was first evalu- ated visually (Table 1), considering the coloration and the sedimentation behavior.

Additionally, the impact of silver-coated textiles on E. coli growing on LB agar plates was investigated. Textile samples were placed on plates coated with bacterial suspensions, and their growth was evaluated after incubation at $37{ }^{\circ} \mathrm{C}$ for $24-48 \mathrm{~h}$. The diameter of the cell-free region was measured and used to calculate the area which was taken as a measure for bactericidal activity.

For the three recipes prepared by the solvothermally driven reduction of $\mathrm{AgNO}_{3}$ similar results were observed as reported recently [29]. A low solvothermal process temperature of $120{ }^{\circ} \mathrm{C}$ led to clear and mostly uncolored solutions, suggesting that this process temperature is not sufficient to lead to a reduction
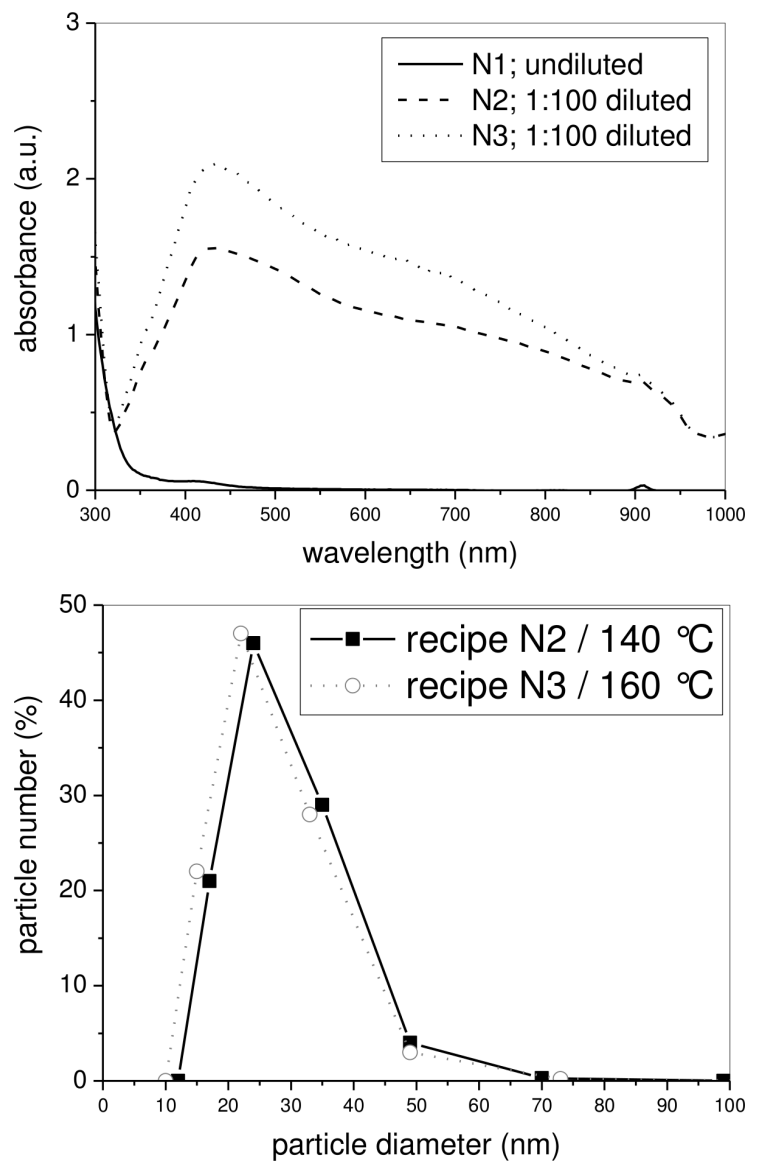

Fig. 1. Solutions containing silver nanoparticles prepared in the solvothermal process. Above: optical spectra of the solutions; the spectra are recorded from undiluted and ethanoldiluted solutions. Below: particle size distribution in solution as determined by light scattering. 
of $\mathrm{AgNO}_{3}$ to elementary silver particles. At temperatures of 140 or $160{ }^{\circ} \mathrm{C}$, brown and turbid solutions were formed indicating the formation of silver particles. The absorption maximum of both solutions in the UV/Vis spectra is around $434 \mathrm{~nm}$ which is typical for silver particles with small diameters (Fig. 1) [39]. The particle size distributions of both recipes N2 and N3 as determined by light scattering has shown that under these conditions almost no particles larger than $70 \mathrm{~nm}$ are formed with the most prominent particle diameter around $23 \mathrm{~nm}$ (Fig. 1). Calculations according to the Mie theory suggested that the absorption maximum of silver particles with a diameter in that range should be a sharp peak around $420 \mathrm{~nm}$ [40]. Any broadening of the peak and a shift of the maximum to higher wavelengths has been explained by different effects, including particle to particle interactions or interactions of the particles with the surrounding medium [40-42].

In contrast to the solvothermally prepared solutions, brown or black solutions were gained by use of the reductive agents ascorbic acid or fructose even at lower process temperatures of $80{ }^{\circ} \mathrm{C}$ (Table 1). It thus appears that with these reductive agents the formation of silver particles is possible at lower process temperatures. However, the stability of the solutions strongly depended on the type of PVP and on the reductive agent. Especially recipe A1 prepared in the presence of PVP K25 with ascorbic acid exhibited a very fast sedimentation leading to black precipitates and a clear and uncolored liquid after only a few hours of storage. Because of the fast sedimentation of recipe A1, no optical spectrum or light scattering could be measured. The black coloration of recipe A1 and the fast sedimentation indicate formation of larger silver particles with diameters up to the micrometer scale. In contrast to recipe A1, recipe $\mathrm{A} 2$ had a brown coloration and high stability against sedimentation owing to the presence of the PVP type K90 with a higher molecular weight compared to PVP K25. Furthermore, the solution of recipe A2 showed an absorption maximum at $446 \mathrm{~nm}$ in the optical spectrum which is related with the diameter of the most common silver particles $(28 \mathrm{~nm})$ as determined by light scattering (Fig. 2).

It appears that polymers with longer chain length are necessary under the chosen conditions to gain a stable solution of silver particles suitable for coating application. This is in good agreement with an earlier investigation using formaldehyde as reductive agent which
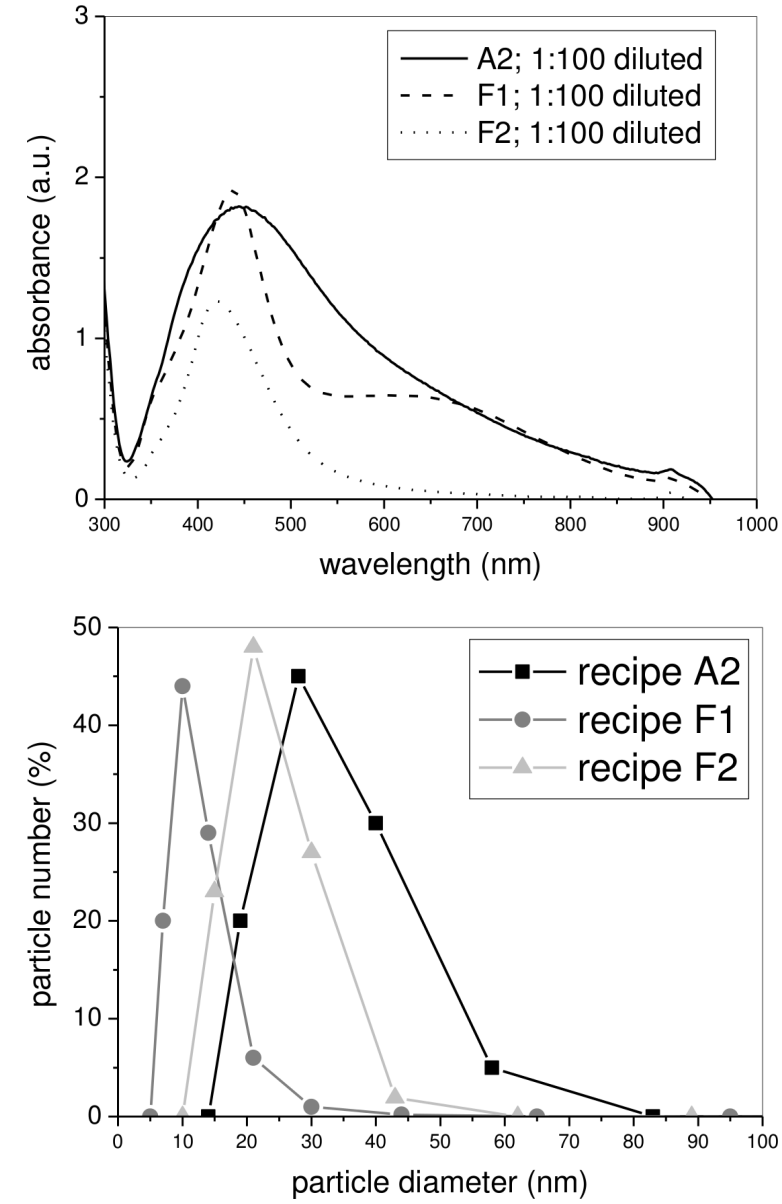

Fig. 2. Solutions containing silver nanoparticles prepared by reduction of $\mathrm{AgNO}_{3}$ with ascorbic acid or fructose under reflux conditions. Above: optical spectra of the solutions; the spectra are recorded from ethanol-diluted solutions. Below: particle size distribution in solution as determined by light scattering.

led also to an insufficient stabilization with low molecular weight PVP [28].

In the case of recipes $\mathrm{F} 1$ and $\mathrm{F} 2$ prepared with the reductive agent fructose, PVP of shorter or longer polymer chain length led to the same brown coloration and a lower tendency to sedimentation. However, for recipe F1 a smaller size of silver particles was determined by light scattering than for F2.

From a similar process with the more strongly reductive agent $\mathrm{NaBH}_{4}$, black solutions resulted exhibiting a slow sedimentation after several days of storage. Light scattering experiments showed that significantly larger silver particles were formed (Fig. 3). The optical spectra of the solutions of recipes B1 and B2 showed 

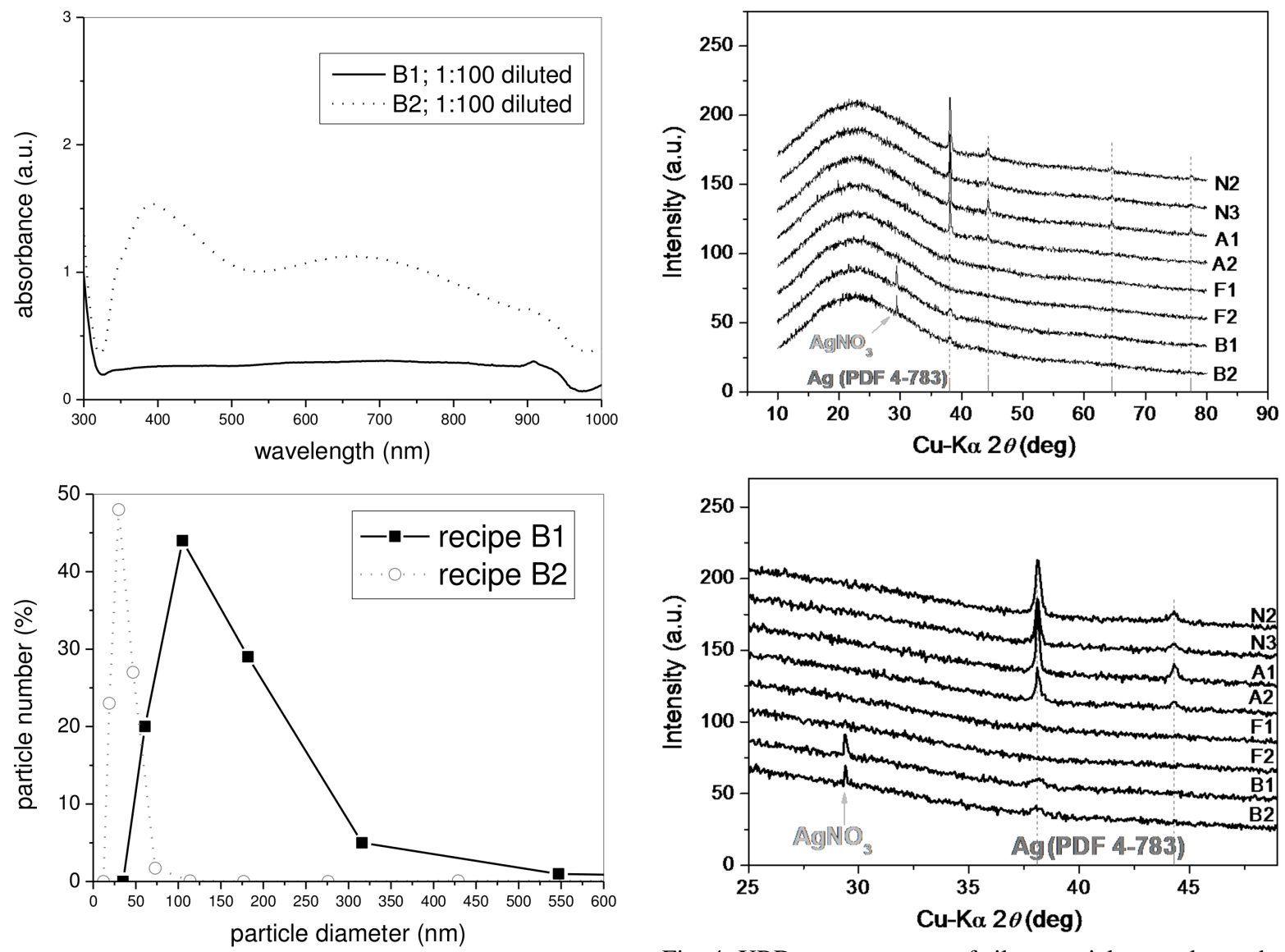

Fig. 3. Solutions containing silver nanoparticles prepared by reduction of $\mathrm{AgNO}_{3}$ with $\mathrm{NaBH}_{4}$ under reflux conditions. Above: optical spectra of the solutions; the spectra are recorded from ethanol-diluted solutions. Below: particle size distribution in solution as determined by light scattering.

broad absorptions over the whole visible range, and for recipe $\mathrm{B} 2$ two maxima in the absorption spectra were detected (Fig. 3). This pattern can be caused by a broad particle size distribution, but also by an anisotropic particle shape [43].

The combination of long-chain PVP as stabilizer with medium and non-toxic reductive agents like fructose or ascorbic acid obviously leads to colloids of promising stability. However, in order to define the quality of the silver particles and to get information, if all $\mathrm{AgNO}_{3}$ is transformed to elemental silver, additional investigations were necessary.

\section{Structural properties of silver particles}

The structural properties of the silver particles were investigated by X-ray diffraction, HR-TEM and SEM.

Fig. 4. XRD measurements of silver particles on glass substrates.

The XRD measurements were performed on samples deposited and dried on glass plates. For both solvothermally prepared recipes $\mathrm{N} 2$ and N3, and for both recipes containing ascorbic acid A1 and A2, the formation of crystalline silver was clearly confirmed by XRD (Fig. 4). The formation of silver particles under reflux conditions and in the presence of ascorbic acid seems to be equivalent to that in the solvothermal process.

By contrast, after using the reductive agents fructose or $\mathrm{NaBH}_{4}$, the peaks indicating the formation of crystalline silver were less prominent. If the process was carried out with $\mathrm{NaBH}_{4}$, peaks for residual crystalline $\mathrm{AgNO}_{3}$ were also detected. The detection of $\mathrm{AgNO}_{3}$ for the recipes B1 and B2 was surprising, because for those recipes the strongest reductive agent was used. Obviously recipes B1 and B2 prepared with $\mathrm{NaBH}_{4}$ are unsatisfactory.

The HR-TEM results for recipe A2 are in agreement with those of the particle size determination by 

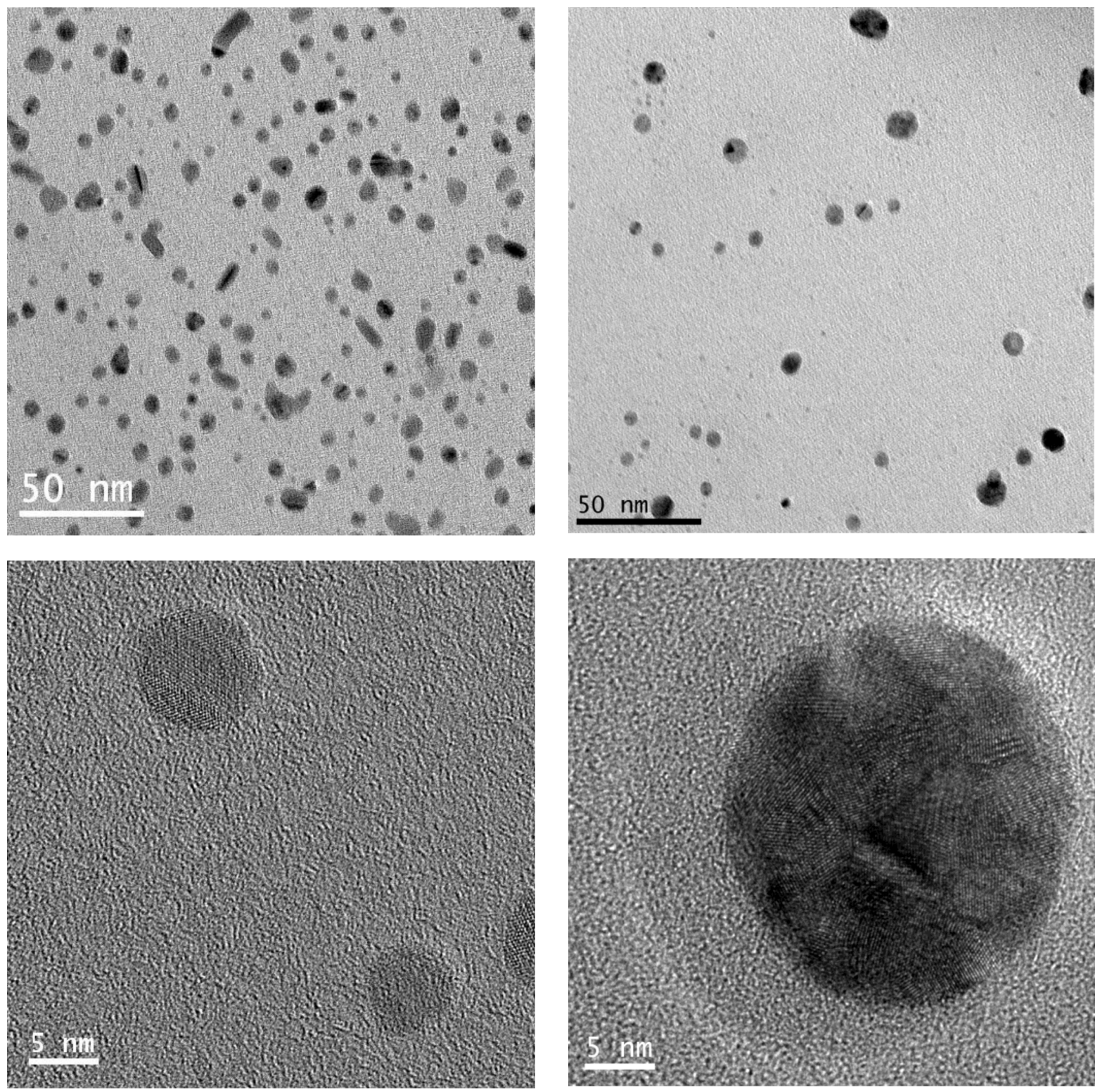

Fig. 5. TEM images of recipe A2 (preparation of silver particles in the presence of PVP type K90 and ascorbic acid).

light scattering (Figs. 2 and 5). The silver particles in the dried samples exhibited a smaller diameter than determined by light scattering in solution. This difference arises, because by HR-TEM the neat silver particles are depicted, whereas by light scattering in solution, the coordinated PVP and the hydrate shell are also detected leading altogether to a larger measured diameter. By means of HR-TEM the shape of the formed silver particles can also be determined.

Fig. 6. TEM images of recipe F1 (preparation of silver particles in the presence of PVP type K25 and fructose).

Only few particles with a rod-like shape were found. From the high-resolution image it is further clearly seen that the silver particles have a crystalline structure (Fig. 5). In the TEM of the recipes F1 and F2, a smaller particle size was also observed compared to the particle diameters measured by dynamic light scattering (Figs. 2, 6 and 7). The silver particles consist of several smaller crystalline parts. The HR-TEM image of recipe B2 exhibited larger particles of diame- 

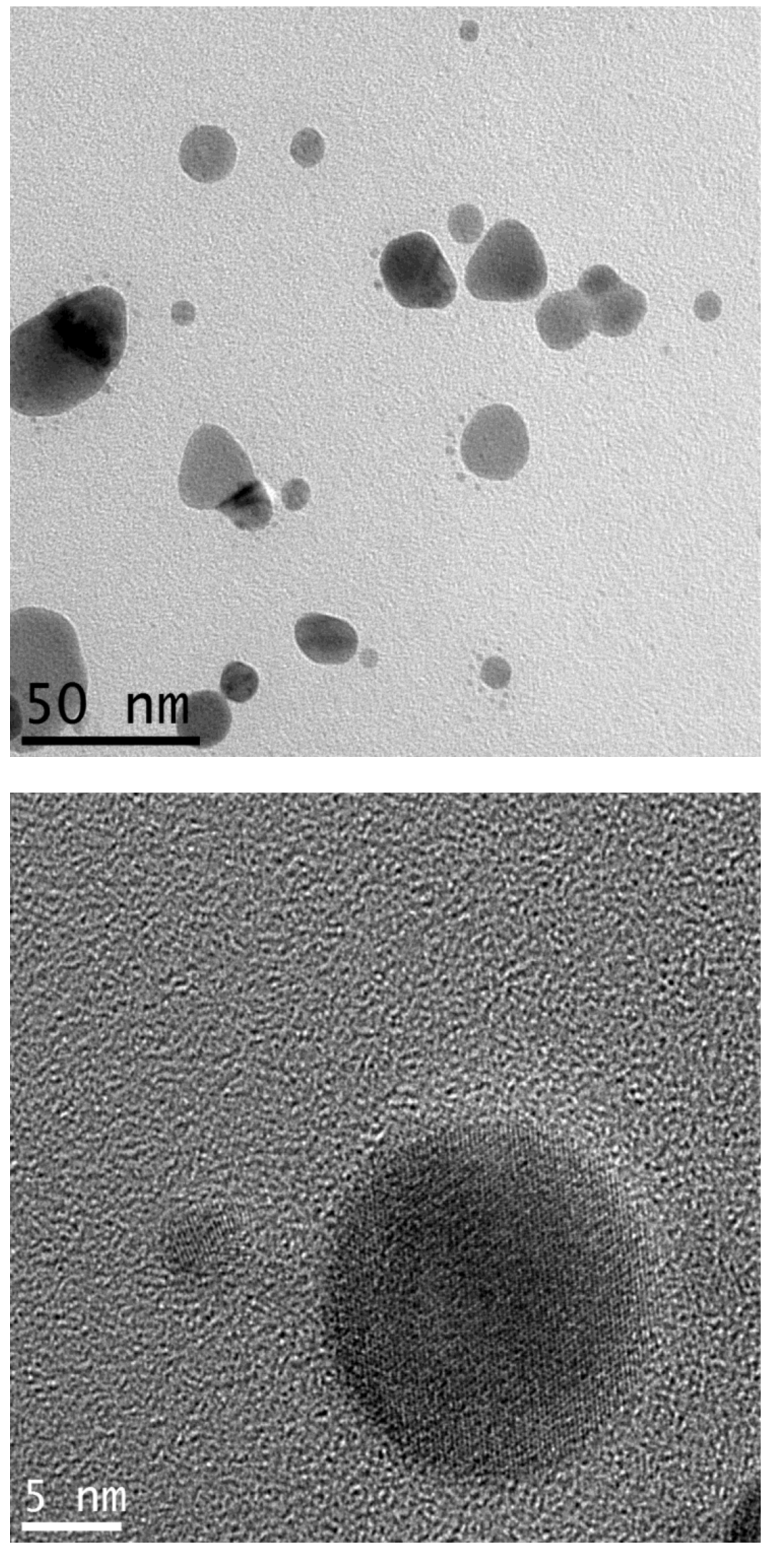

Fig. 7. TEM images of recipe F2 (preparation of silver particles in the presence of PVP type K90 and fructose).

ters up to $50 \mathrm{~nm}$ as expected from the light scattering measurements and the optical properties of this recipe (Fig. 8).

For the recipes $\mathrm{A} 1$ and $\mathrm{B} 1$ with a pronounced sedimentation behavior, no TEM investigations were carried out, because they were not supposed to be suitable as coating agents. However, all prepared recipes were applied on textiles by dip-coating, and a further evaluation after application was undertaken by means of
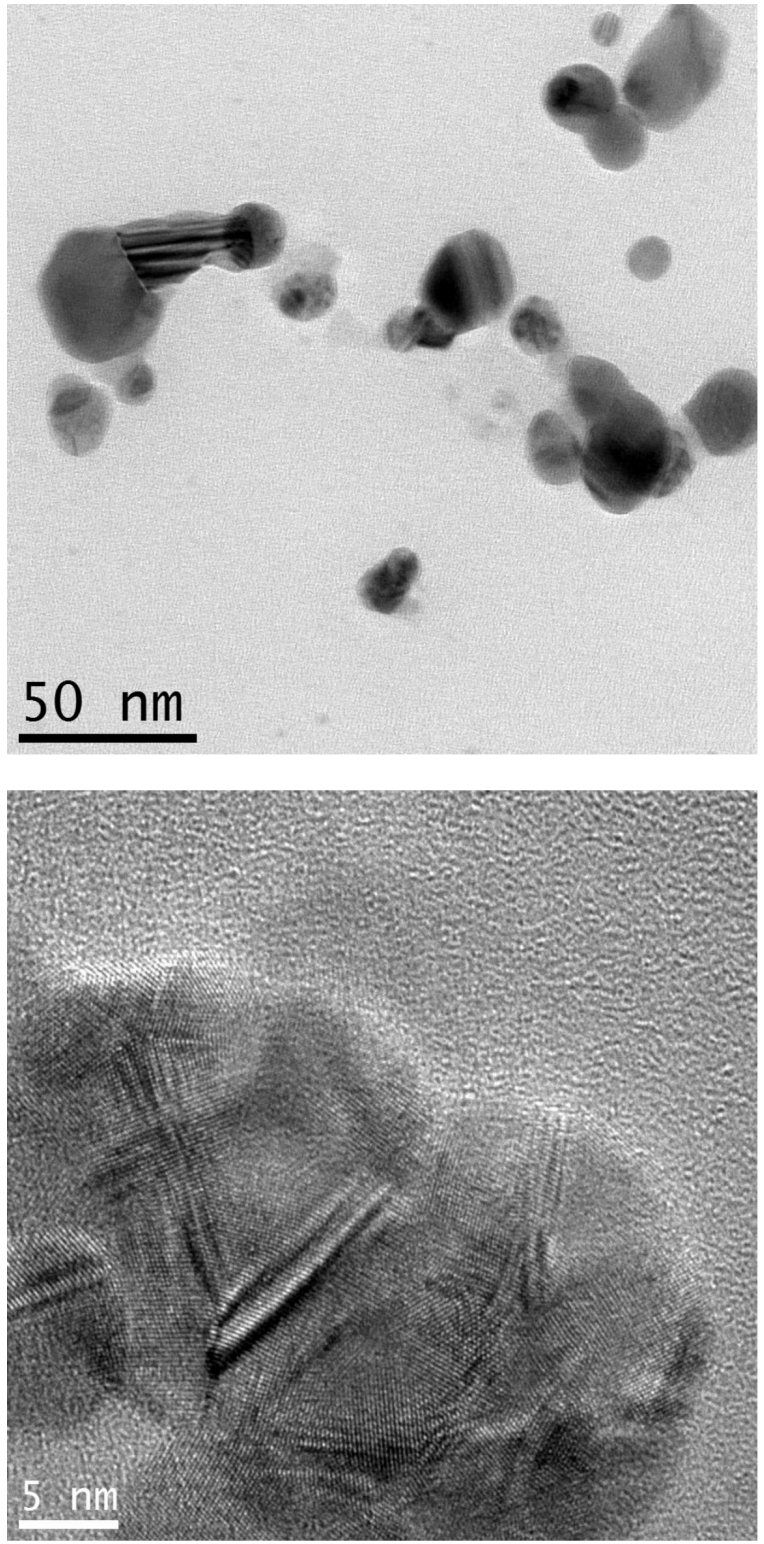

Fig. 8. TEM images of recipe B2 (preparation of silver particles in the presence of PVP type $\mathrm{K} 90$ and $\mathrm{NaBH}_{4}$ ).

SEM. With recipes N2 and N3. spherical particles exhibiting a narrow size distribution were observed on the fiber surface by SEM (Fig. 9). As reported earlier, the solvothermal process for the preparation of particulate silver is an ideal technique to produce spherical silver particles useable for textile treatment [29]. The question therefore arose which of the other new recipes prepared at lower temperatures reached the same quality of textile functionalization. 

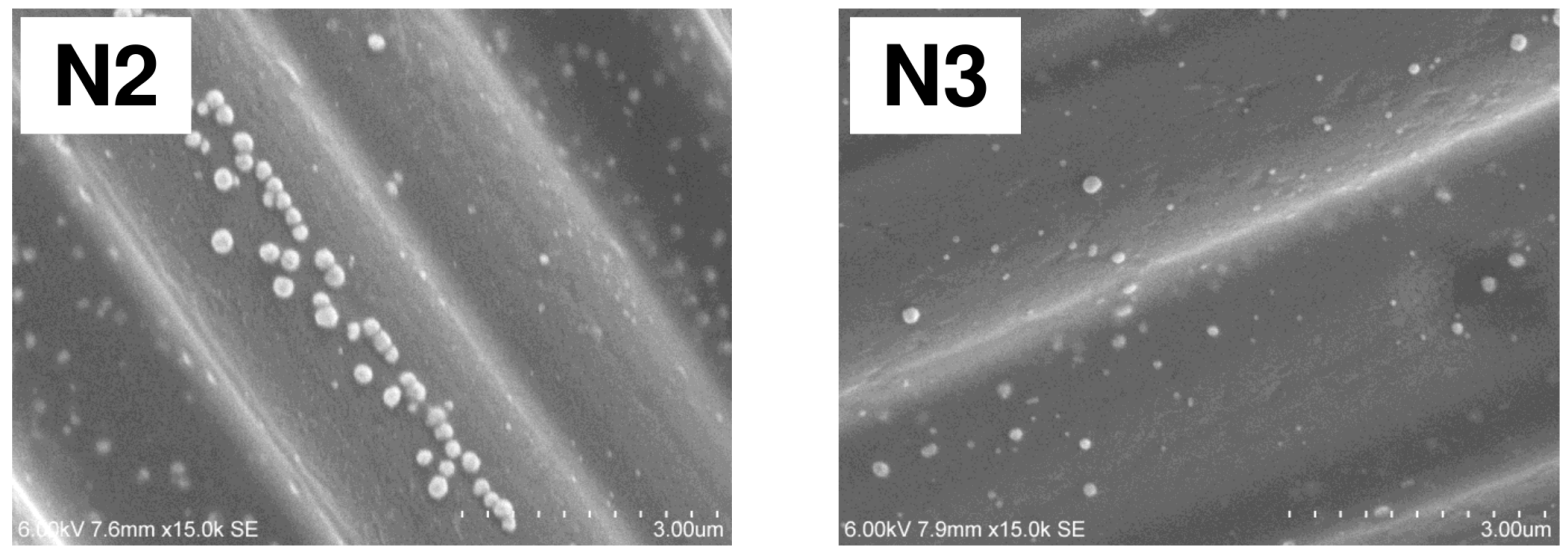

Fig. 9. SEM images of viscose fabrics after application of the silver-containing solutions N2 and N3 prepared under solvothermal conditions.

After treatment with recipe A1 exhibiting rapid sedimentation of silver from the solution, big deposited flakes were discovered by SEM on the textile surface (Fig. 10). The recipes A2, F1 and F2 exhibited the most suitable properties due to the stability of the silver solution and the quality of the formed silver particles. After textile treatment with these three recipes, regularly sized and well distributed particles were detected by SEM on the treated fiber surfaces (Fig. 10). By contrast, after treatment with recipes B1 and B2 containing a broader particle size distribution and a certain trend for sedimentation, on the treated fiber surface larger aggregates are observed (Fig. 10).

\section{Antimicrobial potential of produced materials}

The remaining viability of bacteria cells after contact with textiles treated with the silver-containing recipes is strongly determined by the type of recipe used, but also by the kind of investigated bacteria (Fig. 11). All samples exerted a strong antimicrobial activity against $E$. coli, whereas less efficient inhibition of bacterial growth was observed with $S$. aureus and S. pneumoniae, which also strongly depended on the type of recipe used for textile finishing.

The strong antimicrobial effect against $E$. coli compared to the weaker effectivity against the two other investigated pathogens can be easily explained by the well known stronger antimicrobial effect of silver on gram-negative bacteria such as E. coli [44]. However, for practical applications it is important to prepare silver recipes yielding a strong antimicrobial effect against a broad range of different types of bac- teria. Especially an effect against $S$. aureus is important, because some strains of these bacteria, known as MRSA (Methicillin-resistant Staphylococcus aureus), have acquired resistance against multiple antibiotics, making them a major source for serious nosocomial infections [45]. Therefore, it is important that the silver recipes developed here can also be used for substrate finishing providing high antimicrobial activity against different gram-positive bacteria.

The remaining viability of gram-positive bacteria was found to strongly depend on the type of silver recipe used for the textile treatment (Fig. 11). Especially the recipes N2, A2, F1 and F2 lead to the best reduction of bacterial viability. Other samples resulting from A1, B1 and B2 yield a strong effect against E. coli, but only a small inhibition of the gram-positive bacteria.

The strong antibacterial effect of recipes A2, F1 and $\mathrm{F} 2$ was confirmed in a second arrangement of testing (Fig. 12). The growth of bacteria on an agar plate is strongly inhibited by textiles treated with these three recipes.

From these results, it can be concluded that especially those textile samples modified with silver particles of small and regular size are more effective against a broad range of bacteria. Samples containing larger particles or aggregated particles seem to be less antimicrobially active. Therefore, it appears that the recipes $\mathrm{A} 2$, F1 and F2 are not only promising candidates for application because of their high solution stability and the limited trend to sedimentation, but also because they lead to a broader range of antimicrobial effects. 

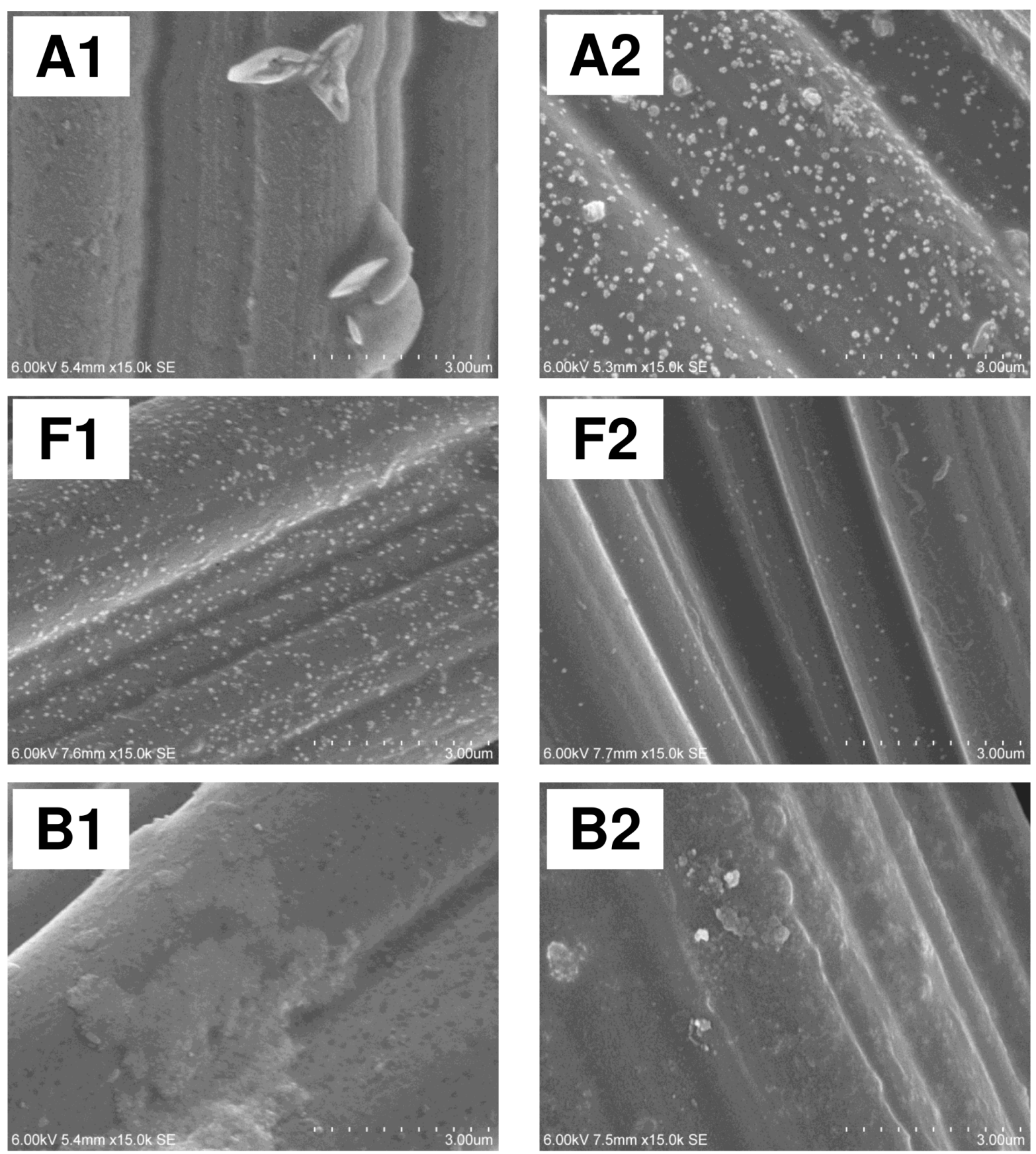

Fig. 10. SEM images of viscose fabrics after application of silver-containing solutions prepared under reflux conditions in the presence of different reductive agents.

\section{Conclusions}

The preparation of colloidal solutions containing silver particles with sizes in the range of 10 to $30 \mathrm{~nm}$ by reduction of $\mathrm{AgNO}_{3}$ under moderate conditions and with moderate and non-toxic reductive agent has been demonstrated to be especially useful to create solutions for textile treatment with the aim of generating 


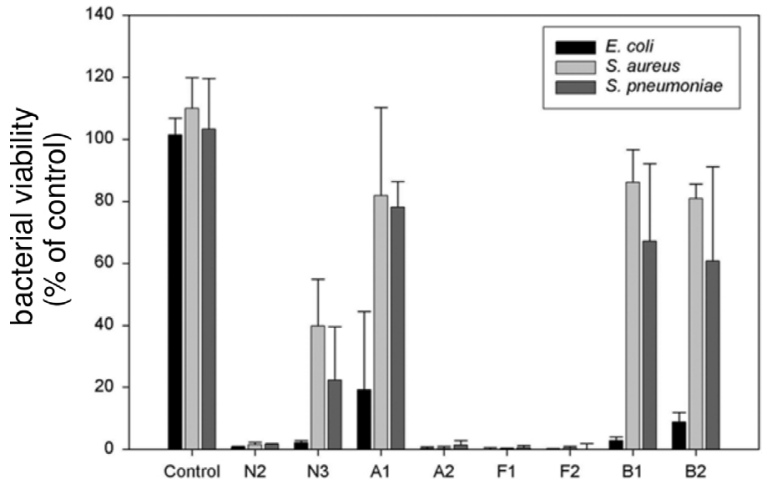

Fig. 11. Antibacterial activity of silver-treated textile fabrics. $E$. coli, S. aureus, and S. pneumoniae were grown for $4 \mathrm{~h}$ at $37{ }^{\circ} \mathrm{C}$ in the presence of silver-coated textile samples as described in the Exprimental Section above. Cellular viability was measured by the MTT assay. Values are expressed as $\%$ viability of bacteria grown in the absence of any textile samples, and are shown as means of $n=4$ independent experiments + S. D.

antimicrobially highly effective textile fabrics. Especially advantageous regarding the stability of the solutions and the antimicrobial activity are recipes containing the stabilizer polyvinylpyrollidone (PVP) with high molecular weight in combination with fructose or ascorbic acid as mild reductive agents. The strong antimicrobial activity of these recipes against gramnegative as well as gram-positive bacteria tested in two experimental settings has proved that the materials could be of interest for practical applications, e. g. preventing the transfer of infectious agents in places such as hospitals, where people with compromised immune function are in need of special protection.

\section{Acknowledgements}

This work was financially supported by the German Bundesministerium für Wirtschaft und Technologie within the research program "Industrielle Vorlaufforschung“ - project number: VF070012 - and the German Bundesministerium für Bildung und Forschung (PT-DLR, Internationales Büro des BMBF) within the framework „Inter-
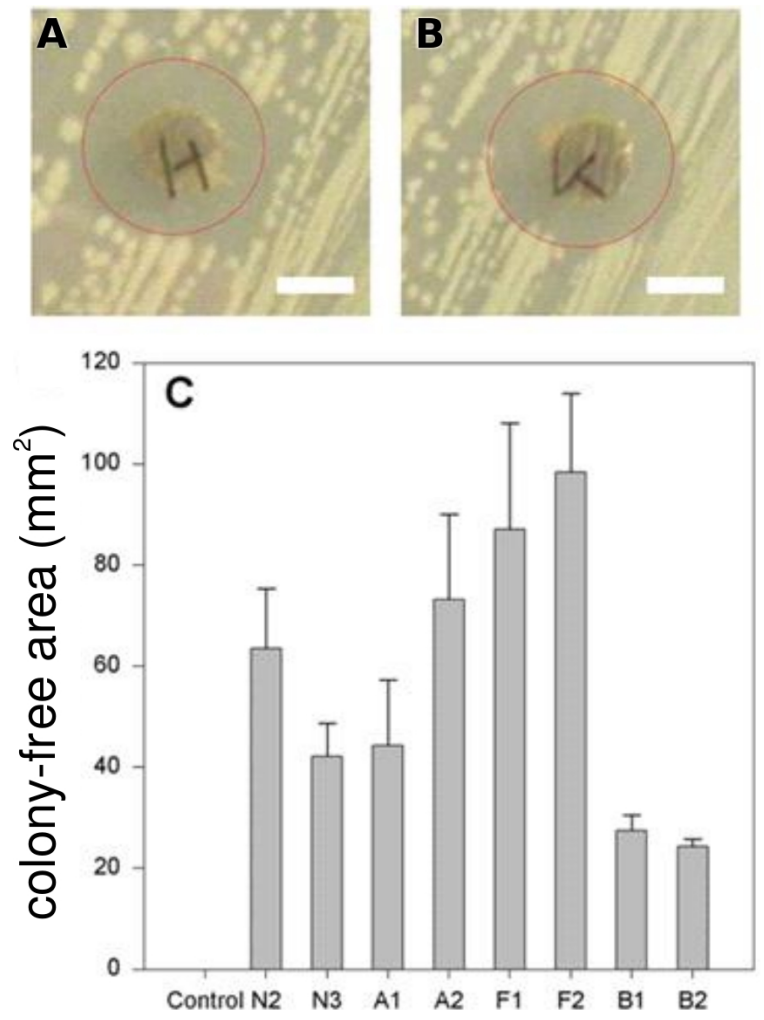

Fig. 12. Antibacterial effect of silver-treated textile fabrics against E. coli. E. coli were grown for $24-48 \mathrm{~h}$ at $37{ }^{\circ} \mathrm{C}$ on agar plates on which silver-coated textile samples had been placed. The area without any bacterial growth was taken as a measure for antibacterial potency of the silver treatment. Representative pictures are shown for the two recipes with the highest bactericidal activity, F1 (A) and F2 (B). White scale bars indicate $5 \mathrm{~mm}$. In (C), values are expressed as the areas without growth of bacterial colonies and are shown as means of $n=3$ independent experiments + S. D.

nationale Zusammenarbeit in Bildung und Forschung mit Korea“ (project number: KOR 08/025). The financial support by the Ministerium für Innovation, Wissenschaft, Forschung und Technologie des Landes Nordrhein-Westfalen is thankfully acknowledged by the DTNW. The authors are very grateful to P. Henker, G. Engelhardt and S. Hebel for expert technical assistance.
[1] M. Kawashita, S. Tsuneyama, F. Miyaji, T. Kokubo, H. Kozuka, K. Yamamoto, Biomaterials 2000, 21, $393-398$.

[2] K. Saengkiettiyut, P. Rattanawaleedirojn, S. Sangsuk, CMU. J. Nat. Sci. 2008, 7, 33-36.

[3] B. Tomsic, B. Simoncic, B. Orel, L. Cerne, P. Forte Tavcer, M. Zorko, I. Jerman, A. Vilcnik, J. Kovac, J. Sol-Gel Sci. Technol. 2008, 47, 44-57.
[4] A. Vilcnik, I. Jerman, A. S. Vuk, M. Kozelj, B. Orel, B. Tomsic, B. Simoncic, J. Kovac, Langmuir 2009, 25 , $5869-5880$.

[5] N. Stobie, B. Duffy, D. E. McCormack, J. Colreavy, M. Hidalgo, P. McHale, S. J. Hinder, Biomaterials 2008, 29, $963-969$.

[6] G. De, D. Kundu, J. Non-Cryst. Solids 2001, 288, 221 225. 
[7] Y. Yao, Y. Ohko, Y. Sekiguchi, A. Fujishima, Y. Kubota, J. Biomed. Mater. Res. B: Appl. Biomater. 2008, $85 B, 453-460$.

[8] R. Nice, US Patent, US4407865, 1983.

[9] C. S. Kim, E. K. Park, S.-G. Kim, J. Sol-Gel Sci. Technol. 2008, 47, 7-15.

[10] B. Mahltig, H. Haufe, K. Muschter, A. Fischer, Y. H. Kim, E. Gutmann, M. Reibold, D. C. Meyer, T. Textor, C. W. Kim, Y. S. Kang, Acta Chim. Slov. 2010, 57, $451-457$.

[11] J. J. Blaker, S. N. Nazhat, A. R. Boccacini, Biomaterials 2004, 25, 1319-1329.

[12] H. Q. Yin, R. Langford, R. E. Burrell, J. Burn Care Res. 1999, 20, 195-200.

[13] S. Haug, A. Roll, P. Schmid-Grendelmeier, P. Johansen, B. Wüthrich, T. M. Kündig, G. Senti, Curr. Probl. Dermatol. 2006, 33, 144-151.

[14] H. J. Lee, S. H. Jeong, Textile Res. J. 2004, 74, $442-$ 447.

[15] H. J. Lee, S. Y. Yeo, S. H. Jeong, J. Mater. Sci. 2003, 38, 2199-2204.

[16] P.C. MacKeen, S. Person, S.C. Warner, W. Snipes, S. E. Stevens, Antimicrobial Agents and Chemotherapy 1987, 31, 93 - 99 .

[17] M. Pollini, M. Russo, A. Licciulli, A. Sannino, A. Maffezzoli, J. Mater. Sci.: Mater. Med. 2009, 20, 2361 2366.

[18] T. Textor, M. M. G. Fouda, B. Mahltig, Appl. Surf. Sci. 2010, 256, 2337-2342.

[19] B. Mahltig, T. Textor, Nanosols and Textiles, World Scientific, Singapore, 2008.

[20] T. Kocareva, I. Grozdanov, B. Pejova, Mater. Lett. 2001, 47, 319-323.

[21] B. Mahltig, E. Gutmann, D.C. Meyer, M. Reibold, A. Bund, H. Böttcher, J. Sol-Gel Sci. Technol. 2009, 49, 202-208.

[22] M. G. Guzmán, J. Dille, S. Godet, Proceedings of World Academy of Science, Engineering and Technology 2008, 33, 367-374.

[23] W.Zhang, X. Qiao, J. Chen, Q. Chen, Mater. Lett. 2008, 62, $1689-1692$.

[24] H. Hirai, Y. Nakao, N. Toshima, J. Macromol. Sci. Chem. A 1979, 13, 727-750.

[25] Z.Zhang, B. Zhao, L. Hu, J. Solid State Chem. 1996, $121,105-110$.

[26] H. Wang, X. Qiao, J. Chen, X. Wang, S. Ding, Mater. Chem. Phys. 2005, 94, 449-453.
[27] A. Slistan-Grijalva, R. Herrera-Urbina, J. F. RivasSilva, M. Avalos-Borja, F. F. Castillon-Barraza, A. Posada-Amarillas, Mater. Res. Bull. 2008, 43, 90-96.

[28] K.-S. Chou, Y.-S. Lai, Mater. Chem. Phys. 2004, 83, $82-88$.

[29] B. Mahltig, E. Gutmann, M. Reibold, D. C. Meyer, H. Böttcher, J. Sol-Gel Sci. Technol. 2009, 51, $204-$ 214.

[30] C. Ducamp-Sanguesa, R. Herrera-Urbina, M. Fiblarz, J. Solid State Chem. 1992, 100, 272 - 280.

[31] G. Carotenuto, G. P. Pepe, L. Nicolais, Eur. Phys. J. B 2000, 16, 11-17.

[32] M. Tsuji, Y. Nishizawa, K. Matsumoto, M. Kubokawa, N. Miyamae, T. Tsuji, Mater. Lett. 2006, 60, 834-838.

[33] P.-Y. Silvert, R. Herrera-Urbina, N. Duvauchelle, V. Vijayakrishnan, K. T. Elhsissen, J. Mater. Chem. 1996, 6, $573-577$.

[34] D. V. Goia, E. Matijevic, New J. Chem. 1998, $1203-$ 1215.

[35] K.-S. Chou, C.-Y. Ren, Mater. Chem. Phys. 2000, 64, $241-246$.

[36] M. Liu, M. Leng, C. Yu, X. Wang, C. Wang, Nano Res. 2010, 3, $843-851$.

[37] Powder Diffraction File 2, Joint Committee on Powder Diffraction Standards - International Centre for Diffraction Data (JCPDS-ICDD), Newtown Square, PA (USA) 2001.

[38] J. Kaltenberg, L. M. Plum, J. L. Ober-Blöbaum, A. Hönscheid, L. Rink, H. Haase, Eur. J. Immunol. 2010, 40, 1496-1503.

[39] U. Kreibig, M. Vollmer, Optical Properties of Metal Clusters, Springer, Heidelberg, 1995.

[40] D. Salz, R. Lamber, M. Wark, A. Baalmann, N. Jaeger, Phys. Chem. Chem. Phys. 1999, 1, 4447-4451.

[41] H. Hövel, S. Fritz, A. Hilger, U. Kreibig, M. Vollmer, Phys. Rev. B 1993, 48, $18178-18188$.

[42] D. Salz, M. Wark, A. Baalmann, U. Simon, N. Jaeger, Phys. Chem. Chem. Phys. 2002, 4, 2438-2442.

[43] T. C. Deivaraj, N. L. Lala, J. Y. Lee, J. Colloid Interf. Sci. 2005, 289, $402-409$.

[44] K. H. Wallhäußer, Praxis der Sterilisation Desinfektion: Konservierung, Georg Thieme Verlag, Stuttgart, 1995.

[45] A. Butterly, U. Schmidt, J. Wiener-Kronish, Anesthesiology 2010, 113, $1453-1459$. 